\title{
The Research on Management in Bad Debt Risk Incorporating Macroeconomic Factors: Empirical Evidence from Chinese Listed Manufacturing Companies
}

\author{
Ting Liu \\ School of Business, Sichuan University, Chengdu 610064, P.R. China
}

\begin{abstract}
Modeling credit and default risk has seen a surge since Moody's KMV mode is proposed during the past two decades and non-financial factors incorporating fluctuation of capital market and macroeconomic status are taken into account in the subsequent research. Despite these notable efforts, few studies numerically reveal the impact that macroeconomic conditions have on the corporate bad debt risk. In this paper, bad debt provision ratio predicts corporate bad debt risk and the panel data of 501 listed manufacturing companies over the period 2004-2013 is used in the fixed-effects model verified by Hausman test to examine the numerical correlation. The model takes both financial ratios and prevailing macroeconomic factors such as GDP growth index, loan interest rate and their lagged terms into account. It shows that corporate bad debt provision ratio is significantly negative correlated with GDP growth index and is significantly positive associated with loan interest rate, which conforms to the replacement of the commercial credit financing theory and provides evidence to manage bad debt risk better in different status.
\end{abstract}

Index Terms - Macroeconomic factors; Accounts receivable; Bad debt risk

\section{Introduction and Theory Analysis}

Bad debt risk is the possibility of loss owing to the default of the credit customers, which is essentially a kind of credit risk; it varies with the changes of borrowers' performance ability. Early research focus on modeling the business default risk. Beaver (1966) finds that the best two discriminant ratios are the quick assets to current liabilities and the net income to total assets. Altman (1968) puts forward a discriminant function to compute the $\mathrm{Z}$ value which includes 5 different ratios, that respectively are working capital/total assets, retained earnings/total assets, earnings before interest and taxes/total assets, market value of equity/book value of total debt and sales/total assets; so we can predict whether the firm is on the verge of bankruptcy or not. The $\mathrm{Z}$ score model is widely used in financial crisis early-warning and has been revised to refer to different countries.

In recent years, the frequency of economic crisis rises gradually, leading that many banks and financial institutions go bankrupt and the economic bubbles burst. Thus, how to exactly assess the credit standing of enterprises for banks and financial institutions comes into focus. In 1993, Moody's KMV mode proposed for the credit standing assessment takes fluctuant factors of capital market into account, able to estimate the default rate of all the publicly traded banks and listed firms, making a great improvement in revision in traditional model. Ruowei Ma (2006) introduces the model into the early-warning of financial distress of Chinese listed companies for the first time, and demonstrates its applicability in China market. Chunfeng Wang et al. (1999) confirm the accuracy of the combining forecasts assessment, where the predictions of statistical technique and neural network are combined to assess the credit risk. In contrast to the KMV mode, Wilson (1998) presents a new model-CPV (credit portfolio view) model evaluating the credit risk allowing for the macroeconomic status; it is widely used in countries all over the world to simulate conditional joint distribution of default rate of varieties of credit products. As the result of joint distribution changing along with macroeconomic elements, such as the GDP growth and interest rate, the loan default rate of the banks decreases and the number of defaulting firms rises in recession (Max Bruche et al. (2010). Kenneth Carling et al. (2007) estimate a duration model for the survival time of firms' credit lines in a bank to state that macroeconomic variables have significant explanatory power for firm default risk in addition to a number of common financial ratios. Benjamin M. Tabak et al. (2011) construct the Minimum Spanning Tree (MST) on further illustration of the distinct effects that macroeconomic variables have on default probabilities and conclude that it is important to take those into account in credit risk modeling.

A number of empirical studies in domestic studies investigate the relation of macroeconomic status and credit risk, basing on regression model. Guanzheng Li et al. (2011) measure the direction and extent of the economic cycle factors and the economic transition factors respectively by conducting an ECTM model, and propose that the increase in diversification degree of enterprise ownership and the financial marketization reform will contribute to the reduction in systemic credit risk. Tingting Tang and Zhaoben Fang (2011) use the logistic model and VAR (vector auto-regression) model to show the non-linear association, where the descending of the money supply affect NPL (non-performing loan) ratio most continuously and most dramatically. Chaolin Zhang et al. (2014) indicate that monetary deflation is positively associated with trade credit, accounts receivable decreasing while the accounts payable increasing during the period of monetary deflation, which is in accordance with the replacement of the commercial credit financing theory .

Most of articles disclose how macroeconomic factors influence the DF (default rate) and how to decrease DF in the perspective of banks, while extant research does not make 
further research on the above mentioned relevance in the terms of corporation. In the increasingly fierce international market, enterprises try to seek the optimum balance of product cost and quality for the purpose of quickly seizing and expanding the market share. Besides, they will ease the credit policy to build up bonds of cooperation with other companies. Accounts receivable is the result of credit selling, i.e. cash payment does not coincide with commodity transaction. Owing to the time difference, it is uncertain to get all accounts receivable back, which means bad debt risk exists objectively. Overdue accounts occupy a large amount of liquid assets, making it difficult in capital turnover and production. Meanwhile, amounts of the written-off accounts receivable will greatly reduce the profits and bring huge losses.

It has been noted that macroeconomic factors and the bank loan default rate are significantly correlated (see e.g. Chanjuan Cheng et al. (2009); Guanzheng Li et al. (2011)). Provision for bad debt rate and bank loan default rates are essentially the same; both are the proportion estimation of uncollectibles. In addition, researchers believe that the bad debt risk is mainly related to the repayment ability and repayment will of the credit customers, which are driven by macroeconomic condition. Thus macroeconomic factors will affect the bad debt risk of the enterprise in theory. For example, the bad debt provision ratio of Shenzhen Cau Technology Co. Ltd rise from $0.07 \%$ in 2004 to $76.73 \%$ in 2008, and then drop to $56.94 \%$ in 2013, while Shenzhen Desay Battery Technology Co. Ltd encounter the same situation, bad debt rate rising from $0.05 \%$ in 2004 to $16.19 \%$ in 2008, then decreasing to 0 in 2013. The aforesaid data objectively exhibits the influence of macroeconomic factors on corporate defaults (as shown in Fig.1).

Based on the above background, this paper carries out an empirical test on the influence factors including macroeconomic factors, taking 501 listed manufacturing companies in China as samples, using the fixed-effects regression model to analyze how macroeconomic factors affect accounts receivable bad debts rate, which will be of great help for enterprise in better controlling the accounts receivable bad debt risk combining macroeconomic situation.

This article proceeds as follows. Section 1 demonstrates the theory of the relevant papers. Section 2 presents the model and data used in the empirical test and the definition of dependent variables and independent variables. Section 3 presents the results of the empirical test. Section 4 concludes.

\section{Data and Model}

\section{A. Data}

The data set used is a panel consisting of 5,010 observations on 501 listed manufacturing companies in the period of 2004 to 2013. This study selects the listed manufacturing companies in China for research samples for two reasons. One is that manufacturing companies both produce and sell products. The subsequent production would be affected to a certain extent along with the decrease of profit when uncollectible accounts occupy a lot of cash. Therefore, it is especially important to manage the bad debt risk of accounts receivable. The other is that manufacturing companies account for more than $50 \%$ of the total listed firms in China, making sufficient observations in the empirical study.

The figure below visually shows the variability of bad debt provision ratio (bdpr) along with the time, in which circle presents individual bdpr of 501 firms in the study while diamond represents the mean of all the samples. Most of individual bdprs converge below 40 from 2004 to 2007 and rise up gradually since 2008 when financial crisis emerges, which is confirmed by overall average. The connected diamond shows that the mean of bdpr rises in 2007, and keep a higher value during 2008 to 2010 . Because of macroeconomic depression in 2008, the financial conditions of enterprises become worse so as to be unable to repay, leading to the rise of bdpr.

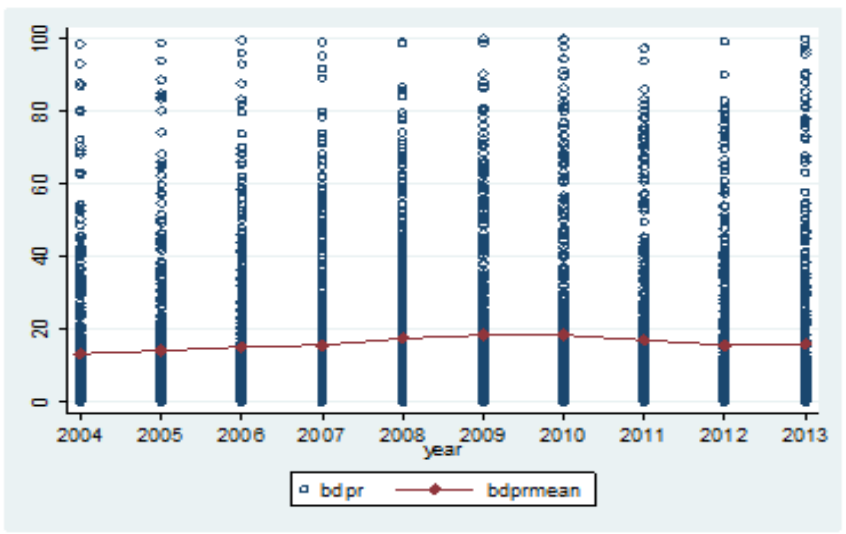

Fig. 1 Bad debts provision rate in different year

The financial data mainly comes from CSMAR database and RESSET database; some data are revised and supplemented combining Shenzhen and Shanghai stock exchange website and Juchaozixun website; macroeconomic data is collected from China's national bureau of statistics web site.

B. Model

Basing on Xin Jiang (2009)'s multiple linear regression, this study takes both firm financial ratios and macroeconomic factors as independent variables while makes bad debt provision ratio dependent variables. In spite of wide use of accounts receivable turnover ratio and bad debt loss rate to assess the bad debt risk in existing literature, this paper chooses the bad debt provision rate (bdpr) in risk measurement, because provision for bad debts is calculated in different proportion according to different age group, the longer the age, the higher the proportion. In consequence, the bad debt provision rate could be perceived as the forecast proportion of the uncollectibles in total accounts receivable, while bad debt loss rate is a historical descriptive data reflecting past loss, making it reasonable that bad debt provision ratio can effectively measure the bad debt risk better. In addition, Tingting Tang and Zhaoben Fang (2011), Xin Jiang(2009), Chanjuan Cheng et al.(2009) take non- 
performing loan ratio to measure the credit risk of commercial banks, which is the ratio of loan with low possibility to collect back in total loan and essentially in accordance with bad debt provision ratio, providing an evidence to adopt the latter practically.

Instead of conducting the regression model inclusive of all the macroeconomic variables, 7 different models are made to accurately present their respective influence on corporate bad debt risk where multicollinearity between macroeconomic factors (Tianyuan Cui, 2012) are eliminated. The empirical models are as follows:

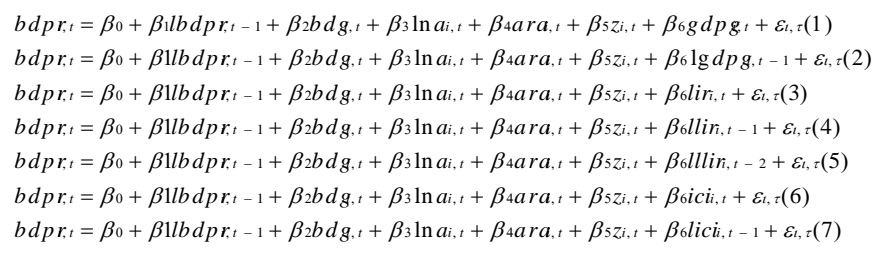

In the above models, $i$ represents different companies ranging from 1 to 501; t represents year in the range of 2004 to 2013. Variables are defined in the following.

Bad debts growth (bdg) explains the rate of current provision for bad debts to the beginning provision, closely associated with the explained variable. Enterprises with larger scale have a preference for risk decision while small ones don't, so size taking the total assets of logarithm (lna) is included. Ara is defined as accounts receivable scale, the percentage of accounts receivable to assets. Because ara is negatively related to corporate profits, see Shihui Guo et al. (2009), enterprises will control the range of the ratio in combination with the industry characteristics and their practical situation, namely the ratio reflecting credit policy to some extent. $\mathrm{Z}$ is computed according to Altman's multivariate financial crisis early-warning z score model and it is of use in estimating the financial condition in the terms of firms(Kairui Liu et al. 2010). The higher $\mathrm{z}$ score is, the better the financial performance is, and the lower various aspects of risk including bad debt risk is. GDP growth index (gdpg) represents a country's overall economic growth and it is the important indicators of macroeconomic conditions. In some ways, it can measure the repayment ability of credit party (Tingting Tang et al. 2011). Loan interest rate (lir) presents corporate cost of possessing loan. When it rises, enterprises are inclined to alternative financing of receivables (Chaolin Zhang et al. 2014) and have no repayment willingness, resulting in higher bad debt risk. Annual data is used in the paper which is adjusted according to weighted average for the month when it changes in a year. Industrial climate index (ici) indicates the economy is in good condition when above the critical value of 100 and in recession when below 100. As a result, this article sets the industry climate index for the dummy variable which equals one if ici is higher than 100 and zero otherwise.

Basing on previously published work and taking the autoregressive model and lagged effects of macroeconomic factors into consideration, this study adds in first-order lag for bad debts provision rate (lbdpr), GDP growth index (lgdpg) and industrial climate index (lici) in the fixed-effects model as well as loan interest rate of first order lag (llir) and second order lag (1llir).

\section{Empirical Results}

This paper uses STATA to examine the numerical correlation and takes fixed-effects model rather than randomeffects model by Hausman test. The results are in the following Tables.

TABLE 1 Multiple regression results for model 1 to 4

\begin{tabular}{|c|c|c|c|c|}
\hline $\begin{array}{c}\text { Independent } \\
\text { variables }\end{array}$ & $(1)$ & $(2)$ & $(3)$ & $(4)$ \\
\hline lbdpr & $0.3974 * * *$ & $0.3991 * * *$ & $0.4018 * * *$ & $0.3959 * * *$ \\
\hline bdg & $0.2459 * * *$ & $0.2434 * * *$ & $0.2421 * * *$ & $0.2433 * * *$ \\
\hline $\operatorname{lna}$ & $-3.096 * * *$ & $-2.627 * * *$ & $-2.4262 * * *$ & $-2.5994 * * *$ \\
\hline ara & $0.994 * * *$ & $1.0143 * * *$ & $1.0198 * * *$ & $1.016 * * *$ \\
\hline zscore & $-1.2532 * *$ & $-1.1094 * *$ & $-1.0219 * *$ & $-1.2265 * *$ \\
\hline gdpg & $-0.3737 * * *$ & & & \\
\hline lgdpg & & $-0.1432 *$ & & \\
\hline lir & & & $-0.4419 * *$ & \\
\hline 1 lir & & & & $0.458 * *$ \\
\hline cons & $117.4627 * * *$ & $81.7601 * * *$ & $64.1508 * * *$ & $62.74 * * *$ \\
\hline R-sq & 0.3807 & 0.3777 & 0.378 & 0.3781 \\
\hline F & 461.33 & 455.58 & 456.01 & 456.24 \\
\hline
\end{tabular}

TABLE 2 Multiple regression results for model 5 to 7

\begin{tabular}{|c|c|c|c|}
\hline \multicolumn{4}{|c|}{ Dependent variable__ bdpr } \\
\hline Independent variables & (5) & (6) & (7) \\
\hline lbdpr & $0.3912 * * *$ & $0.397 * * *$ & $0.3958 * * *$ \\
\hline bdg & $0.2461 * * *$ & $0.2441 * * *$ & $0.243 * * *$ \\
\hline $\ln a$ & $-2.7903 * * *$ & $-2.6214 * * *$ & $-2.6201 * * *$ \\
\hline ara & $1.0094 * * *$ & $1.0139 * * *$ & $1.0156^{* * * *}$ \\
\hline zscore & $-1.2725 * * *$ & $-1.2661 * *$ & $-1.1377 * *$ \\
\hline 11lir & $1.0053^{* * * *}$ & & \\
\hline ici & & $-0.0273 * *$ & \\
\hline lici & & & $-0.0235^{* *}$ \\
\hline _cons & $63.7977 * * *$ & $69.4872 * * *$ & $68.9175^{* * * *}$ \\
\hline R-sq & 0.3812 & 0.3781 & 0.3779 \\
\hline $\mathrm{F}$ & 462.25 & 456.22 & 455.85 \\
\hline
\end{tabular}

$* * *, * *$, and $*$ denote significance at the $1 \%, 5 \%$, and $10 \%$ levels respectively

As can be seen in the above tables, the coefficients are mostly significant and $\mathrm{F}$ value is large, i.e., the models are exactly effective. Size of the enterprises is negatively related to the bad debts provision rate in accordance with the preference for risk decision of large-scale enterprises. Accounts receivable scale is significantly positively correlated with bdpr because accounts receivable scale can reflects a firm's credit policy. The higher ara is, the looser credit policy 
is and the higher bad debt risk is. As stated previously, the higher $\mathrm{z}$ score is, the better the financial performance is and the lower bad debt risk is, so it has a remarkable negative correlation with bdpr.

As for the macroeconomic factors, GDP growth index is more closely negatively related to bdgr than the lagged term. Macroeconomic condition is good when GDP grows a lot along with the better repay ability of credit customers, so the bdpr will decline. Consequently, the enterprises can loosen the credit policy in the prediction of economic prosperity for sales expansion in virtue of bad debt risk. In contrast to GDP growth, the hysteresis of loan interest rate is noticeable. Second order lag for loan interest rate is the most significant with largest coefficient in the three forms, which is in keeping with the replacement of the commercial credit financing theory. As the lir rises, enterprises have to pay more cost due to the possession of bank loans resulting in preference for accounts payable with no extra cost. Therefore, accounts receivable increase in the terms of the creditors. On account of more provision for bad debt in longer age, prior accounts receivable greatly assist in high bad debt provision rate. It is important to take loan interest rate into consideration in the decision of credit sales. Industrial climate index is negatively correlated with bdpr, but the coefficient is small. It can be explained that industrial climate index indicates the overall conditions of industrial firms, but their credit customers are not all in industry, for example, business, so the GDP growth index appropriate for measuring the overall macroeconomic status is more significantly relevant with bdpr.

\section{Conclusion}

This paper contributes to the field for bad debt risk management in the perspective of enterprises taking macroeconomic status into consideration by employing a panel data of 501 listed manufacturing companies over the period 2004-2013 with STATA. Based on the existing research, 7 fixed effects models are used to exactly present the influence that the macroeconomic factors have on corporate bad debt provision rate which predicts the bad debt risk. In the empirical test, both financial ratios and prevailing macroeconomic factors are included for regressions. The result shows that GDP growth index is closely negatively correlated with the bdpr, in accordance with the finding of Tingting Tang et al. (2011). Besides, the hysteresis of loan interest rate is noticeable in contrast to GDP growth, conforming to the replacement of the commercial credit financing theory. Differentiating from the theory that the risk of accounts receivable depends on the financial performance of credit customers and the credit policy of creditors, this study provides evidence that it is also affected by macroeconomic status. Bad debt provision rate declines when GDP grows a lot due to the better repay ability of credit customers.

In conclusion, enterprises should apply strict credit policy when forecast the macroeconomic downturn to avoid high bad debt risk. And in the decision making whether sell goods on credit to certain customers or not, loan interest rate should be considered as well as customers' financial performance to confirm if the customers financing by way of credit trade. Corporate will manage bad debt risk better taking current and predictable macroeconomic factors into consideration.

\section{References}

[1] Benjamin M. Tabak, André Victor D. Luduvice, Daniel O. Cajueiro, 2011, Modeling default probabilities: The case of Brazil, Journal of International Financial Markets, Institutions \& Money, 21,513-534.

[2] Chanjuan Cheng, Haidong Zou,(2009), Toward the Application of CPV Model in the Calculation of Loan Default Probability, Modern Economic Science, 31(5), 15-20.

[3] Chaolin Zhang, Jinming Du, Ke Su, 2014, the Impact of Monetary Deflation to the Corporate Bank Loan and Trade Credit, Statistics and Decision, 10, 152-154B. Simpson, et al, "Title of paper goes here if known," unpublished.

[4] Chunfeng Wang, Haihui Wan, Wei Zhang, 1999, Application of Combining Forecasts in Credit Risk Assessment in Banks, Journal of Industrial Engineering /Engineering Management, 13(1), 5-8.

[5] Edward I. Altman, 1968, Financial Ratios, Discriminant Analysis and the Prediction of Corporate Bankruptcy, Journal of Finance, 23(4), 589$611 \mathrm{M}$. Young, The Technical Writer's Handbook, Mill Valley, CA: University Science, 1989.

[6] Guanzheng Li, Jiangang Peng, Zhihua Lv, 2011, Economic Cycles, Economic Transition and Systemic Credit Risk of Firms: Empirical Study Based on ECTM Model, Journal of Finance and Economics, 27(6), 25-34

[7] Kairui Liu, Ying Mi, 2010, Financial Early-warning and Improving of the Listed Companies Based on Z-Score Model---Taking "Xiangli Stock" as an Example, Technology and Innovation Management, 31(6), 710-713.

[8] Kenneth Carling,Tor Jacobson, Jesper Linde', Kasper Roszbach, 2007, Corporate Credit Risk Modeling and the Macroeconomy, Journal of Banking \& Finance,31,845-846.

[9] Max Bruche, Carlos González-Aguado, 2010, Recovery Rates, Default Probabilities, and the Credit Cycle, Journal of Banking \& Finance, 34:754-764.

[10] Ruowei Ma, 2006, The Empirical Research on KMV Model Applied in the Early-warning of Financial Distress of Chinese Listed Companies, Application of Statistics and Management, 25(5), 593-601.

[11] Shihui Guo, Wenjiao Cui, 2009, Study on the Correlation between Profit Quality and Accounts Receivable of Chinese Listed Companies, Statistics and Decision, 13, 131-134.

[12] Tingting Tang, Zhaoben Fang, 2011, Credit risk of Commercial Banks and Macro Economy-Research Based on Stress Test, Modern Economic Science, 33(4), 66-71.

[13] Thomas C. Wilson, 1998, Portfolio Credit Risk, Economic Policy Review, 10, 71-82.

[14] Tianyuan Cui, 2012, The Empirical Study on Listed Firms' Credit Risk Combining Non-financial Factors, Times Finance, 9, 213-214.

[15] William H. Beaver, 1966, Financial Ratios as Predictors of Failure, Journal of Accounting Research, 5, 71-111.

[16] Xiaoli Sun, Long Peng, 2013, Study on Calculation of Credit Risks Based on KMV Model in China's Internet Finance, Journal of Beijing University of Posts and Telecommunications (Social Sciences Edition), 15(6), 75-81.

[17] Xin Jiang, 2009, Analysis on the Macroeconomic Factors Affecting Credit Risk of Commercial Banks, Modern Economic Information, 12, 25-26. 